\title{
CONSTRUCCIONES DE OPUS QUADRATUM EN CORDOBA
}

\author{
Lourdes ROLDAN GOMEZ \\ Universidad Autónoma de Madrid
}

\section{Resumen}

El presente artículo tiene como objetivo resaltar la importancia de determinados edificios de la provincia y de la ciudad de Córdoba, como jalones en la utilización y difusión de técnicas de construcción romanas en la Provincia Bética. En concreto el opus quadratum, escasamente representado en otras ciudades Hispanorromanas, tiene una abundante utilización en esta ciudad, tanto en época republicana como imperial. Así, podemos considerar la presencia de esta técnica como un modo de prestigiar la ciudad, elegida como capital de la Bética. También se relizaron en opus quadratum los puentes de Villa del Río y Los Pedroches, que pueden ser considerados como elementos fundamentales en las vías de comunicación de la ciudad de Córdoba con otros importantes núcleos urbanos.

\section{Summary}

The object of this work is to value the importance of certains buildings of the province and city of Cordoba in the use and diffusion of the technics of roman construction in the Betica province. In concret, the opus quadratum, scasly represented in other hispanorroman cities had a full use in Cordoba, so much in republican, as in imperial time. Like this, we could considere the presence of this technic like a way to give prestige to the city chosen as the Betic capital. They also made in opus quadratum the bridges of Villa del Río y Los Pedroches, that can be considered as fundamental elements in the roads of comunication of the Cordoba city with other important places.

La provincia de Córdoba muestra diferentes edificaciones extraurbanas que nos permiten un conocimiento de las técnicas constructivas romanas empleadas en época republicana y augustea. Asimismo, la capital de la Betica, a pesar de que su urbanismo no es aún todo lo conocido que sería deseable, muestra buenos ejemplos de adopción y utilización de técnicas romanas en sus primeros momentos. 
Las construcciones rurales, abundantes en esta provincia, han sido ya puestas de relieve en diversas ocasiones, señalando reiteradamente la existencia de una auténtica red hidrográfica que abastecía, tanto las necesidades rurales agrícolas, como urbanas. Baste mencionar las construcciones del Carchena, consideradas silos o construcciones hidráulicas, el acueducto de Ucubi o las impresionantes cistemas de Monturque (1).

Es evidente la utilidad de este tipo de edificaciones debido al bien conocido desarrollo agrícola de la zona, cercana a la capital de la Bética, donde la sequedad del clima hizo de ellas una necesidad ya desde momentos tempranos de la presencia romana. Es probable que dichas construcciones estuvieran, como se ha señalado, en función de una producción cerealista ligada a las villae más antiguas y que supondrían una continuidad con respecto a formas de hábitat anteriores. De hecho, se constata la presencia de construcciones hidráulicas en las llamadas Turres Hannibalis (2), como una continuidad o transformación de las mismas (3).

Aunque no carente de interés el problema de la posible continuidad de asentamientos iberopúnicos en núcleos de población rurales romanos, nos interesa señalar ahora la utilización de técnicas y materiales plenamente romanos en las construcciones hidráulicas de muchos de ellos. Si bien es cierto que, en general, existe una inclinación a considerar estas construcciones de cronología republicana (s. I a.C.) (MORENA LOPEZ y SERRANO CARRILLO, 1991, 117 ss.), creemos que en algunos casos pudieron haberse realizado en el s. I d.C. ya que se ha podido documentar la presencia de ladrillos, que nos inclinan a pensar en una fecha más tardía (por ejemplo en las cisternas del Cortijo Bajo, Las Cotillas (Baena) (IDEM, 119-121) y en el acueducto de Ucubi (4). Algunas otras cisternas, como las de Monturque o los llamados silos de Carchena, documentan una utilización antigua del opus caementicium. El material es de buena calidad, está compuesto por pequeños caementa calizos unidos por argamasa, con un porcentaje del 25-30 \% de cal en la mezcla. Esta proporción entra dentro de las prescripciones vitrubianas que recomiendan 1 parte de cal, por cada tres de arena o 2 de arena y una de puzzolana. Estas construcciones serían una prueba de la utilización en nuestra Península en el s. I a.C. de técnicas de construcción que se estaban empleando en Roma desde, al menos, el s. II a.C. (5). Este fenomeno es paralelo al que se da en algunas ciudades

(1) LACORT NAVARRO, P. (1988, 1989a y 1989b). Ver sobre la utilización del opus caementicium en estas construcciones ROLDAN GOMEZ, 1992a y 1992b (en prensa), con bibliografía anterior.

(2) Las excavaciones de Oswaldo Arteaga en Obulco han dado como resultado una cronología romana, del s. I a.C. para la construcción del recinto fortificado. Contradice, por tanto, la relación de esta fortificación con el mundo púnico, como tradicionalmente se creía. Habrá que considerar la posibilidad de que no sea este el único caso de cronología más tardía a la establecida por FORTEA y BERNIER (1970).

(3) Algunos autores consideran la posibilidad de que los propios recintos se convirtieran en asentamientos rurales (CARRILLO, 1991, 228; CASTRO, 1988, 318; CHOCLAN Y CASTRO, 1990, 211-212). De hecho algunos de los algibes documentados en la Campiña oriental se ubican en los citados recintos (MORENA LOPEZ y SERRANO CARRILLO, 1991, 117 ss.).

(4) Véase sobre este acueducto ROLDAN GOMEZ, 1992a (en prensa), con bibliografía anterior.

(5) El uso del hormigón en la Península Itálica comenzó en Pompeya, donde escaseaba piedra de talla y se desarrolló en relación con el florecimiento de época samnita (LUGLI, 1957, 383). Existen otros ejemplos de 
provinciales donde la introducción del hormigón romano parece fecharse también en los dos últimos siglos de la república (6).

Otros tipos de técnicas característicamente romanas se hallaban también en uso en la Península Ibérica en este mismo siglo. Al margen del empleo del opus signinum, documentado en obras republicanas y cuyos posibles antecedentes en el mundo colonial fenicio púnico están aún sin determinar, nos interesa detenemos en las construcciones de opus quadratum.

La ciudad de Córdoba también proporciona documentación sobre este tipo de opus romano en época republicana. Entre sus realizaciones más antiguas podemos señalar las del puente y la muralla, en las que se constata la utilización de opus quadratum de forma abundante. Estas construcciones serían, junto con la muralla de Tarraco y la de Carmo, las primeras realizaciones hispanorromanas en las que se emplea este tipo de opus en cronología ya romana.

Hay que señalar, no obstante, que la construcción en sillares bien escuadrados, con o sin almohadillado, no es patrimonio romano sino que se encuentra en todos los pueblos antiguos Mediterráneos y así puede constatarse entre los griegos, etruscos, fenicios, cartagineses, etc. De este modo, en la Península Ibérica y especialmente en la zona andaluza contamos con diversos ejemplos antiguos en los que se utilizaron sillares para la construcción y que son especialmente abundantes en el contexto de la colonización fenicia y púnica.

Encontramos sillares bien escuadrados, en necrópolis fenicio-púnicas del Sur Peninsular, que documentan tipologías semejantes a las halladas en las necrópolis de Cartago y Utica (AUBET, 1986, 616-619). Así, por ejemplo, en las necrópolis de Gadir (s. VI-III a.C.) (7); Trayamar(s. VII a.C.); Villaricos (S. VI a.C.); El Jardín (s. VI-IV a.C.)

utilización temprana del opus caementicium en construcciones bien datadas de Alba Fucens, en el 303-302 a.C. y en Cosa, en el 273 a.C. (LUGLI, 1957, 378; GIULIANI, 1990, 166). Las primeras construcciones de hormigón en Pompeya datan del 300-250 a.C., aparecen formando parte de muros construidos con la técnica que Lugli llama "a nervatura litica" (LUGLI, 1957, 380-381). Al final de la época samnitica esta técnica se libera de los pilares de piedra para construir el opus caementicium. En Ronma la utilización del opus caementicium no se conoce con anterioridad a finales del s. III a.C. (templo de la Magna Mater, 204 a.C. y Porticus Aemilia, 174 a.C., con paramento de opus incertum) (LUGLI, 1957, 363 ss.; ADAM, 1989, 83, RAKOB, 1983, 362). Los ejemplos anteriores al s. II a.C. son escasos y mal conocidos. La técnica debió generalizarse en los dos últimos siglos de la república, suplantando entonces a los anteriores muros de opus quadratum y opus latericium (FURLAIN Y BISSEGER, 1975, 167).

(6) En general, en el área de Italia central, las técnicas romanas como el opus caementicium, o el incertum, se introdujeron en el s. II a.C. (TORELLI, 1983; Ling, 1985, 23). A finales del s. II a.C. y comienzos del s. I a.C., el opus caementicium, sobre todo para cimientos y núcleos, en unión con el opus incertum, para los alzados, fueron utilizados en diversas construcciones inspiradas en los modelos de los grandes centros helenísticos (templo de la Fortuna Primigenia en Praeneste; templo de Hércules en Tivoli; templo de Júpiter Anxur en Terracina (GULLINI, 1989, 70 ss.; SEAR, 1989, 24-27).

(7) La forma de cista gaditana oscila entre la estructura tosca de grandes losas monolíticas y la cista construida de sillares perfectamente escuadrados y paredes enlucidas por el interior (GARCIA Y BELLIDO, 1975, 397; AUBET, 1986, 616; con posterioridad MUÑOZ, 1983-84, 47 y ss.). Así, por ejemplo, la cista en la que se halló el sarcófago de la dama de Cádiz, en 1980, en la C/ Ruiz de Alda, estaba realizada mediante sillares de caliza, bien escuadrados, en cuyo interior se había tallado la forma del sarcófago (CORZO, 1980, 15). Recientemente 
(8), se utilizaron sillares, en algunos casos con una gran perfección técnica, para la realización de cistas (Gadir, El Jardín) o grandes cámaras (Trayamar, Villaricos) (AUBET, 1986, 620-622). También aparece el empleo de sillares, en contextos funerarios más tardíos, ibero-turdetanos, como es el caso de las necrópolis de Toya y Galera (s. IV a.C.), aparentemente por influencia de las anteriores (9). En los poblados ibéricos costeros es frecuente el empleo de la piedra -sillares más o menos regularizados- en la construcción de las murallas (10); también se documentan en los recintos amurallados de la Bética -las llamadas por Plinio Turres Hannibalis- como El Higuerón, fechado a comienzos del s. IV a.C. (FORTEA y BERNIER, 1970, 108-110) o la fortaleza de Ibros (Jaén), este último con anathyrosis (véase nota 2).

Algunos ejemplos pueden constatarse también en el contexto de la colonización púnica y griega. Entre estos últimos hay que señalar la impresionante obra de la muralla de Carmona cuyo cuidado y perfección técnica están a la altura de las mejores realizaciones helenísticas (JIMENEZ, 1989, 183 ss.) (Lám. 1.a).

En este ambiente púnico helenístico hemos de considerar la introducción de la arquitectura plenamente romana en la Bética, como una evolución, en muchos casos, de elementos anteriores. Se muestra así una definida tendencia, en el empleo de materiales, al mantenimiento de las tradiciones junto con un buen aprovechamiento de la geología local.

Volviendo al ejemplo de Córdoba, ya en época romana, tanto en las construcciones citadas como en otras, de cronología republicana o augustea, e incluso, imperial, parece ser una constante el empleo del opus quadratum. No se documenta, en general, la presencia de otros opera, como el incertum, reticulatum, o testaceum abundantes en ciudades provinciales o en la propia Roma. No obstante, el reciente hallazgo y excavación de un impresionante edificio, villa señorial, de finales del s. III o comienzos del s. IV (11), viene a documentar la reutilización de sillares así como el empleo de una

se han publicado los trabajos de urgencia llevados a cabo en la ciudad de Cádiz desde 1979 (PERDIGONES y OTROS, 1990). Al margen ahora de los hallazgos novedosos de enterramientos de cremación de época fenicia (s. VI), tenemos los trabajos de la necrópolis púnica (desde inicios del s. V a.C.), con tumbas de sillería paralelizables a los hallazgos en Jardín e isla de Ibiza (IDEM, 33 y ss.).

(8) Trayamar (SCHUBART y NIEMEYER, 1976, 130); Villaricos (SIRET, 1908; ASTRUC, 1951; AUBET, 1986, 620); El Jardín (ARTEAGA, 1979, 261-272 y 1981, 293-295).

(9) ALMAGRO BASCH, 1975; SCHUBART, 1975; más recientemente, PEREIRA, 1989, 477 ss. con bibliografía anterior. En el caso de Toya no son sillares por completo rectangulares sino que se trata más bien de un aparejo de tipo trapezoidal que se utilizó asimismo en diversos recintos amurallados del mundo griego helenístico.

(10) En este sentido recientemente se ha publicado las Actas del Simposi Internacional D'Arqueologia Ibèrica. Fortificacions. La problemàtica de L'Ibèric Ple:(segles IV-III a.C.). Manresa 1991. Se presentan estados de la cuestión sobre las fortificaciones de la Cataluña Occidental, Central y Costera; la Zona Central y Parte Norte del País Valenciano; Valle Medio del Ebro; Desembocadura del Ebro; Alta Andalucía y Turdetania. El enfoque de los trabajos es de recopilación e inventario, más que un análisis pormenorizado de las estructuras. Excepción de ello, relacionándolo con el contexto Mediterráneo es el trabajo de MORET "Facteurs Indigènes et Exogènes dans L'Évolution de L'Architectue défensive Ibérique”, 265-271 publicado en dichas Actas.

(11) Los datos sobre la excavación de esta villa cordobesa fueron expuestos en las Jornadas de Arqueología Andaluza celebradas en Granada en 1992. 
técnica mixta, compuesta por sillarejo (opus vittatum) y ladrillo, que fue muy abundante en las ciudades provinciales (12) pero que no había sido apenas documentada hasta ahora en las construcciones urbanas de la Bética.

De nuestros datos sobre edificios actualmente visibles y de las referencias sobre otros ya ocultos, deducimos que los edificios públicos de Córdoba estuvieron realizados, en su mayoría, en opus quadratum, como correspondería a una capital provincial (ROLDAN GOMEZ, 1992c). Así, por ejemplo se documentó en la citada Avda. del Gran Capitán (IBAÑEZ, 1985, 97-100); en la C/E. Quero, 11, en el límite sur del pavimento del foro (IBAÑEZ y OTROS, 1985a, 127-130) y en la C/ Córdoba de Veracruz, donde se hallaron varios muros de sillares romanos, uno de ellos almohadillado; un pavimento de opus signinum; arquillos y piezas de hypocaustum (IBAÑEZ y OTROS, 1985b, 131-136), por citar algunos ejemplos.

El material más empleado fue, por tanto, la piedra y la técnica por excelencia el opus quadratum, con o sin estructura caementicia.

Las referencias existentes para época republicana muestran que ya para entonces y, probablemente desde el momento de la fundación de la ciudad, se empleaba este tipo de técnica. Así se documenta en la muralla de la zona norte, realizada a base de gruesos lienzos de sillares y, en algunos puntos, relleno interior en opus caementicium (con piedras de tamaño mediano y grande sin ninguna colocación y argamasa de unión) (Lám. 1.b). No existe, en este caso, colocación de los sillares a soga y tizón al modo griego, ni al modo romano, aunque sí una alternancia en la que predominan los tizones. Unicamente, en el caso de los torreones, vemos un mayor cuidado en la colocación de los sillares pero siempre se procura la alternancia de las juntas. Los sillares están unidos a hueso y sus medidas son uniformes, especialmente en la altura.

Otros edificios de época republicana fueron realizados en opus quadratum así, en el puente se documentaron sillares de $70 \mathrm{~cm}$., bien labrados y de técnica similar a los de la muralla. También las termas (SANTOS GENER, 1955, 87) y el edificio excavado junto al posterior foro (probable foro de época republicana) (MARCOS y VICENT, 1985, 248), estuvieron realizados asimismo en sillares.

La misma técnica se empleó en la realización de la estructura del foro, supuestamente augusteo (STYLOW, 1990, 273): el muro de sillares de la C/ Ramírez de Arellano que fue destruido (IBAÑEZ, 1985, 127-130). Del mismo, se documentó el pavimento de grandes losas realizado en un tipo de caliza micrítica gris, muy diferente a la empleada

(12) Fue muy frecuente la alternancia de los bloques de opus vittatum con hiladas de ladrillo. Estos, o bien constituían hiladas de una o dos filas, a intervalos regulares de altura; o bien alternaban una hilada de bloques de piedra con una, o dos, de ladrillos. En la Península Itálica el opus vittatum se utilizó, sobre todo, en ciudades del centro y el norte a partir del s. II a.C. Generalmente se documenta la introducción de hiladas de ladrillo posteriormente, como en la Liguria, a partir de época Flavia (PALLARES, 1986, 10 ss.). En la Galia fue utilizado habitualmente, desde época de Augusto, hasta el final del Imperio (BEDON y OTROS, 1988, 74) introduciéndose, en época trajanea, las hiladas de ladrillo y conviviendo ambos tipos. Este tipo mixto, con hiladas de ladrillo y núcleo de hormigón, tuvo un uso sistemático en las fortificaciones de finales del s. III d.C. (ADAM, 1989). 
en los paramentos. Se trata de una caliza dura que no es adecuada para su talla en forma de sillares pero cuya estratificación permite más fácilmente la obtención de losas.

Más tarde, entrado ya el s. I d.C. se continuó utilizando el mismo tipo de técnica para la construcción del templo, situado en la C/Claudio Marcelo. El opus quadratum, que por entonces ya había sido bien experimentado en la Península, se utilizo, tanto para la realización de subestructuras, como para los alzados.

En la construcción del templo se documenta que, prácticamente, todos los muros de infraestructura están realizados en opus quadratum. Este se complementa, en ocasiones, con núcleos de opus caementicium o con rellenos más sencillos de tierra. Así sucede en unos contrafuertes en "abanico", que sustentan la plataforma ante el templo, y en la subestructura de la cella (Lám. 2.a).

El mismo tipo de técnica se empleó en las estructuras que pueden verse en el patio del Museo Arqueológico (Lám. 2.b) y cuyo uso está aún por determinar (13). Están realizadas a base de una gran cantidad de sillares que rellenarían una amplia plataforma macizándola en su parte delantera (Fig. 1). Así se consiguió un aterrazamiento que apoyaba finalmente sobre la roca natural y que pudo servir de asentamiento constructivo para un gran edificio o planificación urbanística. Como complemento, para nivelar la superficie sobre la que se asentaban los sillares, se empleo una base de hormigón que se adaptaba al terreno.

La utilización de estructuras de sillares macizas como cimentación de grandes edificios (14) fue muy utilizada en Roma, especialmente antes de la difusión del opus caementicium (ADAM, 1989, 116). Los sillares que se empleaban para ello eran los que resultaban defectuosos en la talla (Vitrubio, 2, 7, 5), por lo que no es extraño encontrar en estos sillares ciertas irregularidades e, incluso, algunos acabados innecesarios. Los muros de los cimientos debían ser, logicamente de mayor anchura que los del alzado y su profundidad dependía del terreno, ya que se excavaba hasta encontrar terreno firme y, a ser posible, la roca. En el templo de Córdoba los cimientos llegaban a una profundidad de $4 \mathrm{~m}$., que junto con el grosor de las cimentaciones, especialmente en la cella, haría necesaria la utilización de un gran número de sillares.

La escalera del templo, el ara frente a él y los contrafuertes documentan un tipo de

(13) Stylow considera que en esta zona, entre las calles Angel Saavedra y Jesús y María se ubicó el foro provincial y el centro del culto imperial provincial. En época flavia, la anterior plaza pública, donde ya desde época Julio-Claudia se desarrollaría el culto imperial con carácter colonial, sería convertida en centro provincial "seguramente con una restructuración y tal vez ampliación de la plaza" (STYLOW, 1990, 278). Considera que el límite sur de la plaza estaría a la altura de la C/ Alta de Santa Ana y C/ Saravia, en la zona en que comienza el gran declive de la ciudad. Las estructuras del Museo Arqueológico, podrían haber formado parte de esta restructuración y ampliación de la plaza, constituyendo quizás un acceso monumental hacia la gran plaza y su templo.

(14) La cimentación, siguiendo a Giulini, es un elemento esencial en la construcción ya que recoge el peso de toda la estructura y lo transmite al terreno en forma más uniforme posible y en medida compatible con la capacidad portante de aquel. Tiene por objeto asegurar al edificio la máxima estabilidad por un periodo de tiempo indeterminado (GIULIANI, 1990, 119). 
cimentación lineal simple, también en sillares y con relleno de tierra, que se complementaba con una capa de hormigón como remate.

La cronología del templo indica que se utilizó este tipo de cimentaciones basada en los sillares en un momento en que se había abandonado su uso en Roma (a partir del s. II a.C.), para optar por el hormigón, más rápido, fácil y barato que la talla de sillares. Su elección en el templo de Córdoba así como en las estructuras del Museo Arqueológico indica, como es frecuente en la arquitectura provincial, una escasa confianza en el opus caementicium, como sucede en Asia Menor, Britania o la Galia (BUTLER, 1983; LING, 1985, WAELKENS, 1987), que se traduce frecuentemente en su menor empleo en las cimentaciones, su combinación con ladrillos para los alzados, etc.

El módulo de los sillares utilizados en ambos edificios es muy semejante, variando únicamente en lo referente a la anchura, que es más irregular. Todas ellas están comprendidas entre 90 y $110 \mathrm{~cm}$. para las longitudes y entre 40 y $60 \mathrm{~cm}$. para las alturas, las anchuras oscilan entre $35 \mathrm{y} 80 \mathrm{~cm}$. Estas medidas son, a su vez, diferentes a las de los sillares empleados en la muralla, que miden desde 90 hasta $200 \mathrm{~cm}$., y cuya altura es más irregular (30-60 cm.). No se da, por tanto, regularidad absoluta en las medidas como tampoco fue habitual en Roma (15).

Así pues, es general para Córdoba la utilización del opus quadratum para todo tipo de construcciones, a diferencia de lo que ocurre en otras ciudades de la Bética. Con respecto a la muralla, no es extraño el tipo de aparejo utilizado pues existen otras murallas de época republicana construidas en opus quadratum. Carmona, Niebla, Tejada la Nueva son algunos ejemplos de ello (JIMENEZ, 1977, 223 ss.); en otros casos, como en Carteia e Itálica, se hicieron en piedras más o menos regulares. Para época Imperial es más general el empleo de otros tipos de aparejos para la realización de los recintos amurallados, generalmente diferentes al opus quadratum. No obstante, es posible documentar en algunos casos, como también sucede con frecuencia en La Galia o en otras provincias, el empleo de sillares reutilizados de edificios anteriores, en las fortificaciones del s. III en adelante.

En relación con el templo de la C/ Claudio Marcelo, ya de época imperial, su comparación con otros templos de ciudades como Belo o Munigua (por proponer sólo los más cercanos y de cronología semejante), muestra que el edificio de Córdoba es el único realizado, por completo, en opus quadratum y constituye, por tanto, un ejemplo más en las construcciones cordobesas. Al margen de ello existen, en otras ciudades fuera de la Bética, templos también realizados en opus quadratum (Ampurias, Barcelona, Evora).

Fuera de la ciudad, existen también importantes construcciones en opus quadratum. Queremos resaltar especialmente, por sus peculiares características constructivas, dos

(15) Lugli ofrece numerosos ejemplos de medidas de sillares para edificios, sobre todo para época republicana, en los que se puede constatar las diferencias existentes en las medidas de los sillares (LUGLI, 1957, 194-199). 
realizaciones en opus quadratum no urbanas, como jalones de la introducción y utilización de las técnicas constructivas romanas en nuestra Península. Se trata de los puentes de Villa del Río y de Los Pedroches, ambos cercanos a la capital de la Bética y elementos esenciales en la red de comunicaciones de la ciudad.

El puente de Villa del Río en la vía Augusta, sobre el río Salado de Porcuna, está situado a las afueras del pueblo, junto al puente nuevo de la carretera Nacional. Durante muchos años sirvió al trazado antiguo de esta calzada, hasta la construcción de un nuevo puente en 1964. Su conservación es buena aunque con diversas remodelaciones fruto de su uso continuado.

El puente, conocido de siempre dada su ubicación, ha sido estudiado o referenciado por diversos autores. Así, por ejemplo, entre las simples referencias, está recogido en el Catálogo Monumental de la Provincia de Córdoba y citado por CEAN BERMUDEZ $(1932,349)$ y THOUVENOT $(1973,514$ ss.). Fue estudiado más a fondo por García y Bellido, quien señalaba, ya en 1965, las características más importantes de su arquitectura: el almohadillado, las dovelas engatilladas y el peculiar enlace de las dovelas de los arcos laterales con las de los arcos de alivio (GARCIA Y BELLIDO, 1965, 143-144), incluyendo un dibujo sobre el mismo y diversas fotografías. Por aquel entonces el puente se hallaba oculto por los derrubios de ladera en todo su lado derecho por lo que no fue posible una documentación completa del mismo. También fue recogido por Fernández Casado quien lo relacionaba con el puente de Mérida sobre el Guadiana dentro del prototipo de puentes republicanos, que generalmente llevan arquillos de aligeramiento (FERNANDEZ CASADO, 1974, sp.).

Más recientemente Sillières ha incluido este puente en su estudio sobre las vías de la Hispania Meridional como elemento fundamental en la documentación de la vía Augustea, señalando también sus características constructivas más relevantes (SILLIERES, 1991, 672-681).

Tanto García y Bellido como Sillières coinciden en la cronología adjudicada al puente, considerándolo de época augustea debido, fundamentalmente, a sus características constructivas avaladas, en el estudio de Sillières, por los datos viarios.

Se trata de un puente de estructura asimétrica, formado por un gran arco central que está flanqueado por otros dos más pequeños, y un tercero en el lado derecho (visto aguas arriba) (Lám. 3.a), el izquierdo no es visible actualmente, por lo que no es posible saber si existió en origen. La limpieza del cauce del río permite hoy documentar en el lado derecho toda la estructura del puente, parte de la cual, como hemos dicho, no era visible en el dibujo realizado en su día por García y Bellido.

La luz del arco central es de 8 '90 m. mientras que las de los dos laterales que lo flanquean son desiguales, de $3 \mathrm{~m}$. y 3’50 m. de derecha a izquierda respectivamente, disminuyendo aún más en el caso del extremo derecho (hasta 2'60 m.). La diferente luz de los arcos provoca alturas distintas de los mismos, a pesar de que se compensa levemente con el arranque más bajo del salmer del arco central con respecto a los 
laterales. Aún con todo, la mayor altura de aquel provoca un perfil alomado que aún se mantiene a pesar de la remodelación sufrida por la parte superior del puente (16).

Lleva arquillos de aligeramiento o aliviaderos, cuya luz es de poco más de un metro (1'10 m.) y su altura de 1'88 m. (Lám. 3.b). Este elemento se asocia generalmente a época republicana o augustea aunque se utilizo hasta época imperial y con cierta frecuencia en época de Trajano, especialmente en las provincias (GAZZOLA, 1963, 128). Los ejemplos más conocidos son el puente Milvio (de fines del s. II a.C.) (IDEM, 33-34), el puente Emilio y el de Calamone, en la Via Flaminia (IDEM, 33 y 88-89) (de época augustea). En la Península el de Mérida sobre el Guadiana (Augusteo) (ALVAREZ MARTINEZ, 1981, 63) y el de Villa Formosa (Alter do Chao, Portugal) (GAZZOLA, 1963, 122-123) (comienzos del s. II d.C.) (Sillières, 1991, 680).

La construcción del puente de Villa del Río está realizada en opus quadratum, en un tipo de piedra caliza de Sierra Morena, o gres rojo (llamada piedra molinera), también característica de otras construcciones cercanas. El almohadillado, que originalmente llevaba, se ha conservado en gran parte sobre la superficie de la piedra (Lám. 4.a).

Actualmente, se pueden ver remodelaciones en la rosca del arco central y en el arco izquierdo, ambas realizadas con grandes ladrillos. Son originales los dos arcos de la derecha y casi todo el central, con algunas remodelaciones en las que se han incrustado ladrillos. Toda la parte superior del puente está reconstruida con sillares sin terminación almohadillada.

La estereotomía de los sillares es bastante homogénea. Son especialmente regulares en cuanto a medidas de altura, pero está colocados de forma aleatoria, sin que se aprecie una altemancia definida a soga y tizón. El módulo de los sillares utilizados es de 80-120 $\mathrm{cm}$. de longitud, $50-70$ de grosor y entre 40 y $50 \mathrm{~cm}$. de altura. No se puede establecer en ellos la utilización del pie romano imperial de 29 ' $57 \mathrm{~cm}$. de forma estricta, aunque sí la constatación de este patrón medida con cierta ambigüedad, lo que no es raro en las construcciones de la Bética romana (ROLDAN GOMEZ, 1992c).

Tanto las dovelas como todo el aparejo presenta terminación de almohadillado, en algunos casos es muy pronunciado, pudiendo apreciarse perfectamente las huellas diagonales del puntero utilizado para la talla, más menudo y denso en los planos de anathyrosis que en el almohadillado propiamente dicho (Lám. 4.a). Por el contrario, en otros casos, debido al desgaste de la piedra, la terminación original se ha perdido casi por

(16) Con respecto a las medidas existen variaciones entre cada uno de los autores que han realizado mediciones. Así, Espinosa midió 9’10 m. para la luz del arco central; Fernández Casado, 9'30 m.; García y Bellido, 9 m. Sillières, 8'90 m. y nosotros hemos medido también $8^{\prime} 90 \mathrm{~m}$. En el caso del arco lateral izquierdo y lateral derecho García y Bellido midió 2'82 m. y 3'60 m.; Sillières 2'70 m. y 3'55 m. y nosotros hemos medido $3 \mathrm{~m}$. y $3^{\prime} 60 \mathrm{~m}$. respectivamente. Para el arco más pequeño de la orilla derecha las mediciones han sido de Espinosa 2 '25 m.; Sillières 2'25 m. y nuestra medición ha dado 2'30 m. Por último, los arquillos de aligeramiento miden de altura 1'85 m. y de anchura 1'10 m. el de la izquierda y 1'14 m. el de la derecha según García y Bellido; para Sillières ambas 1'88 m. de altura y 1'18 de anchura y nosotros hemos medido la misma altura y 1'10 m. de anchura (cfr. GARCIA Y BELLIDO, 1965, 143 y SILLIERES, 1991, 674). 
completo. Los planos de anathyrosis conservados miden entre 6 y $14 \mathrm{~cm}$. de anchura y su almohadillado es irregular, pudiendo documentarse de 2 a $12 \mathrm{~cm}$.

El puente tuvo tajamares triangulares, algo redondeados, en la fachada de aguas arriba. Están constituidos por sillares almohadillados, bien colocados, que se insertan perfectamente en el pilar correspondiente.

Entre las peculiaridades constructivas de este puente, combiene resaltar la forma de apear los arcos menores sobre el dovelaje de los arquillos de aligeramiento, de manera que las dovelas de estos constituyen una de las jambas de aquellos (Lám. 3.b). Se trata de un procedimiento peculiar que no conocemos en otros puentes de nuestra península. Solamente algo similar se utiliza en el puente Calamone sobre la via Flaminia (GAZZOLA, 1963, 88-89; SILLIERES, 1991, 677).

Una segunda peculiaridad es la utilización de dovelas engatilladas en la rosca de los arcos, tanto en el central como en los laterales, e incluso, en los arquillos de aligeramiento (Lám. 4.a). Se pueden ver también en algunos sillares del intradós del arco central. Este procedimiento debió tener carácter técnico, ya que evita el deslizamiento de las dovelas, pero apenas se usó en la arquitectura romana y, en todo caso, es más habitual en construcciones tardías y, sobre todo, medievales islámicas.

Los paralelos romanos que generalmente se citan de ello son los de una tumba de la Via Appia, datada en la segunda mitad del s. II a.C. y el teatro de Orange (17) (LUGLI, 1957, 354), en este caso se observan dovelas engatilladas no de arcos sino formando las platabandas de las puertas de acceso a la scaena, tanto desde el postscaenium (valva hospitalia), como desde las versura (Lám. 5.a). A ellos habría que añadir el tetrapylon de Caparra en cuyo interior las dovelas están talladas en planos escalonados de forma semejante al Mausoleo de Teodorico en Ravena (18) y el puente de Los Pedroches, también en Córdoba y muy cercano al de Villa del Río. Se documentan asimismo dovelas engatilladas en construcciones medievales como el puente árabe de Pinos Puente, los arcos de Santa María del Naranco (únicamente la clave) y en uno de los arcos añadidos a la puerta de Sevilla en Carmona (19) (Lám. 5.b). Por último, en la puerta tardorrepublicana de la muralla de Tarragona, llamada del Socors, junto a la torre de San Magín, existen dovelas semejantes en un arco que Hauschild consideró perteneciente a una remodelación del s. XVI (HAUSCHILD, 1973-74, 32) (Fig. 2).

El engatillamiento o escalonamiento de sillares en los paramentos de los muros es más habitual que en el dovelaje de los arcos. Fue frecuente en el mundo griego, en aparejos rectangulares irregulares que, a veces, se combinaron con aparejos trapezoidales. En

(17) Lugli considera que esta fórmula se utilizó para conseguir una mayor solidez (LUGLI, 1957, 354).

(18) Según García y Bellido este despiezo es inexplicable, a no ser por un alarde técnico de puro lucimiento en el que el arquitecto quiso exhibir sus conocimientos en esterotomía... aquí totalmente inútiles (GARCIA Y BELLIDO, 1974, 13).

(19) A. Jiménez cita algunos paralelos de este elemento constructivo, cuya función era asegurar la estabilidad del arco. Se trata, según Jiménez, de un recurso utilizado sobre todo de época medieval con antecedentes en el mundo romano (JIMENEZ, 1989, 198). 
ambos tipos se producen acoplamientos de las piedras en escalon, más para adaptar las diferentes alturas de las mismas, que por una cuestión de solidez en el muro. Estos tipos de muros no tienen una cronología precisa ya que se encuentran con frecuencia en fortificaciones de los siglos V, IV o III a.C. en Grecia y Asia Menor (MARTIN, 1964, 385). En el Norte de Africa también se utilizaron con frecuencia en época helenística, así, por ejemplo, en el mausoleo de Souk el Gour, en Lixus, Sala, Tamuda, Volúbilis, etc. (JODIN, 1988, 74). En la arquitectura romana el uso de engatillamientos en el paramento fue más puntual, se recurre a esta fórmula generalmente por cuestiones técnicas pero siempre de forma muy específica. Se documentan, sin embargo, ejemplos de ello en todas las provincias (20).

En el puente de Villa del Río no se utilizó esta forma de acoplamiento de los sillares de fachada sino el engatillado de las dovelas que, como hemos dicho, constituye una forma de composición de los arcos bastante peculiar. Su realización bien pudo deberse a una originalidad del arquitecto además de las cuestiones técnicas a las que alude Sillières (21).

La cronología augustea que se ha propuesto para el puente (GARCIA Y BELLIDO, 1965, SILLIERES, 1991) no entra en contradicción con las características arquitectónicas del puente, siendo su paralelo más cercano el puente de Mérida sobre el Guadiana (ALVAREZ MARTINEZ, 1981). No obstante, ninguna de las cuestiones que han llevado a proponer esta cronología son determinantes. Los arquillos de aligeramiento se encuentran también con frecuencia en las provincias en puentes de época imperial, aunque en Italia, como ha señalado Sillières, son más comunes en un momento más antiguo y hasta época de Augusto (SILLIERES, 1991, 680). También la terminación almohadillada del paramento podemos encontrarla, sin salir de la Bética, desde época prerromana a la imperial y fuera de ella en numerosos puentes entre los cuales baste recordar los de Mérida, Martorell, Alcantarillas, de época augustea y Alcántara, Alconetar, etc., ya en época imperial. Se trata también de una terminación habitual en puentes de la Península Itálica, especialmente para época augustea, como puede verse en la obra de Gazzola (GAZZOLA, 1963, 87-89).

Otros elementos característicos de este puente, como son el apoyo de los arcos sobre las dovelas de los respectivos arquillos o el engatillado de las dovelas, son tan peculiares y minoritarios que no es posible establecer una cronología a través de ellos. Si bien el puente de Calamóne, para el primero de estos elementos corresponde también a una cronología augustea, los paralelos de las dovelas engatilladas son tan dispares que

(20) No existe mucha documentación al respecto en las publicaciones pero hemos podido comprobarlo en los análisis constructivos realizados para el Proyecto de Estudio de Técnicas de Construcción en la Hispania Romana que realizamos en el Depto. de Arqueología de la U.A.M., bajo la dirección de M. Bendala.

(21) Según este autor, el conjunto de peculiaridades de este puente se explican por el régimen muy irregular del Arroyo Salado. Así, la presencia de dovelas engatilladas contrarresta el efecto de debilidad del gran arco central y la ausencia de un piederecho en los arcos secundarios, manteniendo la estabilidad de la construcción, SILLIERES, 1991, 677. 
resultan por completo incoherentes. Los ejemplos más cercanos serían la tumba de la via Apia del s. II a.C. y las platabandas de la scaena del teatro de Orange (LUGLI, 1957, 354355) de época augustea, además del Puente de los Pedroches que generalmente se fecha en relación con el de Villa del Río. Así pues, como ya señalaron García y Bellido y Sillières parece haber una mayoría de elementos coincidentes cronologicamente en época augustea que nos llevan a la misma conclusión.

El puente de los Pedroches, es aún más desconocido que el anterior, lo que resulta agravado por una deficiente conservación de su estructura original, que ha sufrido numerosas remodelaciones a lo largo de los años. Sin duda, el estudio más completo que se ha hecho sobre él, al margen de anteriores referencias, es el de Sillières y es poco lo que se puede añadir sobre el mismo (SILLIERES, 1991, 681-686). Está situado sobre la vía Augustea y serviría, según este autor, tanto a ésta, como a la vía Corduba-Emerita.

Se trata de un puente de 3 ojos, con vano central mayor y 2 laterales de $2 \mathrm{~m}$. de luz y 2’30 m. de altura (Lám. 4.b). La anchura en el arco central es de 4'80 m., al margen de los tajamares de la cara norte y los contrafuertes, añadidos posteriormente, al lado sur. Conserva restos de dos tajamares triangulares en su lado norte, aguas arriba, hechos en bloques de piedra macizos.

Se conserva in situ, de época romana, el arco central y quizás parte del arco derecho. Este presenta un dovelaje del mismo tipo de piedra pero mucho más alargado con reintegraciones en ladrillo. El arco de la izquierda (oeste) está rehecho en su totalidad con piedra de menor tamaño trabada con argamasa en el intradós, mientras que el extradós es en ladrillo. También se conservan, realizados en sillares de época romana, los dos pilares centrales y los apoyos exteriores de los arcos pequeños. El resto del alzado está hecho en sillarejo (piedras irregulares) con revoco muy perdido y ladrillos en algunos puntos.

La línea de imposta apoya sobre cuatro hiladas de sillares que constituyen los piederechos del arco, teniendo éste un total de 8 dovelas a cada lado de la clave.

Los sillares presentan siempre un facetado-biselado triangular que se observa en el intradós de los 3 ojos, que es semejante al que puede verse en los sillares de la Puerta de Sevilla en la muralla de Carmona. Este acabado es habitual en ciudades púnicas, aunque se documentan también ejemplos en la Península de época romana como es el caso del templo de la C/ Claudio Marcelo en Córdoba (ROLDAN GOMEZ, 1992c).

Las hiladas se colocaron de forma alterna, a soga y tizón, respondiendo a la llamada por Lugli maniera romana (LUGLI, 1957, 181). Las medidas de los sillares son bastante regulares, especialmente en la altura que oscila en hiladas de $40-50 \mathrm{~cm}$. mientras que en las otras dimensiones existen 2 módulos, uno muy regular de $60-65 \mathrm{~cm}$. y otro de $80-110$ $\mathrm{cm}$., que deben corresponder a la colocación de los sillares a soga y tizón.

Como en el caso del puente de Villa del Río, se le da una cronología Augustea por su relación con aquél, tanto en su proximidad geográfica, como en alguna de sus características técnicas. La presencia en este puente de un recurso tan peculiar como las dovelas 
engatilladas nos hace pensar, junto con otros autores, que ambos fueron coetáneos e incluso hayan podido ser realizados por la misma persona.

Los citados ejemplos, tanto urbanos como rurales, sirven para mostrar la abundante utilización del opus quadratum en los edificios de Córdoba. Es, por tanto, el elemento más destacable en la construcción de los edificios romanos de Córdoba el empleo generalizado del opus quadratum, con o sin estructura caementicia.

Este hecho contrasta con la escasa utilización de este material en otras ciudades de la Bética en fechas aproximadas, como Carteia, Belo, Munigua, e incluso, Itálica. En estos yacimientos, especialmente en los dos primeros, se documenta el empleo del opus quadratum sólo en determinadas partes de los edificios, generalmente las más visibles o que requieren elementos monumentales. En la ciudad de Córdoba esta idea se ha llevado a su máximo grado, al construir todos los edificios y, por completo, en opus quadratum. Se trata de una forma de magnificar la ciudad, que iría acompañada de otros símbolos externos, como decoraciones arquitectónicas, inscripciones, dedicaciones de estatuas, etc., bien conocidas en algunos lugares de la ciudad y que han servido para trazar las hipótesis sobre la ubicación de algún edificio como el foro provincial (STYLOW, 1990, 274-282).

El empleo de la misma técnica en los citados puentes no resulta tan peculiar como en las construcciones urbanas, ya que la utilización de la piedra y, en concreto, del opus quadratum en la construcción de puentes es bastante habitual en el Imperio romano (como puso de manifiesto la citada obra de Gazzola). Sin embargo, en este caso, muestran también el cuidado de ambas construcciones ligado, lógicamente, a la importancia de las vías de comunicación en las que se ubican.

\section{Bibliografia}

ADAM, J.P. (1989): La construction romaine. Materiaux et techniques, París.

ALMAGRO BASCH, M. (1975): “Las raíces del Arte Ibérico”, Saguntum, Papeles de Laboratorio de Arqueología de Valencia, 11, pp. 251-279.

ALVAREZ MARTINEZ, J.M. (1981): El puente y el urbanismo de Augusta Emerita, Madrid.

ARTEAGA, O. (1979): “'Avances sobre las nuevas excavaciones en el Cerro del Mar. Campaña de 1976”, N.A.H., VI, pp. 261-272.

ARTEAGA, O. (1981): “'Cerro del Mar. Campaña de 1978”, N.A.H., XI, pp. 293-295.

ASTRUC, M. (1951): La Necrópolis de Villaricos, Informes y Memorias, 25, Madrid.

AUBET, M.E. (1986): "'La necrópolis de Villaricos en el ámbito del mundo púnico peninsular', Homenaje a Luis Siret, Sevilla, pp. 612-626.

BEDON, R., R. CHEVALIER y P. PINON (1988): Architecture et urbanisme en Gaule Romaine, París.

BENICHOU-SAFAR, H. (1982): Les tombes puniques de Cartago, París. 
BUTLER, R.M. (1983): “The construction of Urban Defences", Roman Urban Defences in the West, London, pp. 125-129.

CASTRO, M. (1988): “"El poblamiento romano de las campiñas occidentales del Alto Guadalquivir. El Imperio”, Actas del I Congreso Peninsular de Historia Antigua, II, pp. 315-331.

CHOCLAN, C. y M. CASTRO (1990): "La campiña del Alto Guadalquivir en los siglos I-II d.C. Asentamientos, estructura agraria y mercado", Arqueología Espacial 12. Seminario sobre Arqueología Espacial, Teruel, pp. 205-221.

CEAN BERMUDEZ, J.A. (1932): Sumario de las antigüedades romanas que hay en España, Madrid.

CORZO, R. (1980): "El nuevo sarcófago antropoide de la necrópolis gaditana", Boletín del Museo de Cádiz, II, pp. 13-24.

FERNANDEZ CASADO (1974): Historia del puente en España, Madrid.

FORTEA, J. y J. BERNIER (1970): Recintos y Fortificaciones Ibéricos en la Bética, Salamanca.

FURLAIN, V. y P. BISSEGGER (1975): “Les mortièrs anciens. Histoire et essai d'analyse scientifique', Zeitschrift für Schewizenrische Archäologie und Kunstgeschichte, 32, pp. 166-178.

GARCIA Y BELLIDO, A. (1965): “El puente de Villa del Río(Córdoba)”, Oretania, 21, pp. 142-150.

GARCIA Y BELLIDO, A. (1974): "Arcos honoríficos romanos en Hispania”, Hispania Romana, Madrid, pp. 7-27.

GARCIA Y BELLIDO, A. (1975): “Protohistoria: Tartessos, Colonización púnica y colonización griega, en R. Menéndez Pidal Historia de España I, 2, (3ª ed.), pp. 281-680.

GAZZOLA (1963): Ponti Romani, Florencia.

GIULIANI, C.F. (1990): L'Edilizia nell' antichità, Roma.

GULLINI, G. (1989): “'Tradizioni e innovazione nelle fasi edilizie del Santuario della Fortuna Primigenia tra el III e il I s. a.C.', Urbanistica ed Architettura dell' antica Praeneste, Palestrina, pp. 69-86.

HAUSCHILD, TH. (1973-1974): “La puerta romana de la muralla de Tarragona", Boletín de la Real Sociedad Arqueológica Tarraconense, 121-124, Tarragona, pp. 23-33.

IBAÑEZ, A. (1985): “Memoria de la investigación arqueológica practicada en el yacimiento de la Avenida del Gran Capitán (Córdoba)", Anuario Arqueológico de Andalucía, II, pp. 97-100.

IBAÑEZ, A. y OTROS (1985a): "Intervención arqueológica de urgencia en el solar de la C/Eduardo Quero, nº 11 de Córdoba”, Anuario Arqueológico de Andalucía, III, pp. 127-130.

IBAÑEZ, A. y OTROS (1985b): "Excavación arqueológica de urgencia en la sede del I.N.S.S. en la calle Córdoba de Veracruz (Córdoba) 1985', Anuario Arqueológico de Andalucía, III, 131-136. 
JEDRZEJEWSKA, H. (1967): "New methods in the investigation of ancient mortars", Archeological Chemistry, Symposium, Filadelfia, pp. 147-166.

JIMENEZ, A. (1977): “Arquitectura romana de la Bética. Introducción al estudio de las fortificaciones", Segovia y la arqueología romana, Segovia, pp. 223-238.

JIMENEZ A. (1989): La Puerta de Sevilla en Carmona, Sevilla.

JODIN, A. (1988): Volubilis Regia Iubae. Contribution à l'étude des civilisations du Maroc antique preclaudien, París.

LACORT NAVARRO, P.J. (1988): “Acueducto romano en los términos de Nueva Carteya, Castro del Río y Espejo (Córdoba). Abastecimiento de agua a la C.C.I. Ucubi”, Actas del I Coloquio de Historia Antigua de Andalucía, Córdoba, 1988.

LACORT NAVARRO, P.J. (1989a): Economía agraria íbero-romana en el Valle Medio del Guadalquivir: infraestructura rural, Córdoba.

LACORT NAVARRO, P.J. (1989b): "Infraestructura hidráulica de época romana en la Campiña de Córdoba"', Memorias de Historia Antigua IX, Oviedo, pp. 51-82.

LEZINE, A. (1964): Architecture romaine d'Afrique. Recherches et mises au point, París.

LING, R. (1985): “The mechanics of the Building Trade", Roman Urban Topography in Britain and the Western Empire, Londres, pp. 14-27.

LUGLI, G. (1957): La Tecnica edilicia romana, con particolare rigardo a Roma e Lacio, Roma.

MARCOS, A. y A.M. VICENT (1985): "Investigación, técnicas y problemas en solares de la ciudad de Córdoba y algunos resultados topográficos generales", Arqueología de las ciudades modernas superpuestas a las antiguas (Zaragoza, 1983), Madrid, pp. 231-252.

MARTIN, R. (1964): Manuel d' Architecture Grecque, París.

MORENA LOPEZ, J.A. y J. SERRANO CARRILLO (1991): “'Obras hidráulicas en la campiña oriental de Córdoba (Baena-Cañete)", II Encuentros de Historia Local. La Campiña, Córdoba, pp. 117-150.

MUÑOZ VICENTE, A. (1983-84): “ Aportaciones al estudio de las tumbas de sillería prerromana de Cádiz", Boletín del Museo de Cádiz, 4, pp. 47-54.

PALLARES, F. (1986): “Le technique murarie di Albintimilium”, Riv. St. Lig, 52, pp. 5-58.

PERDIGONES, L., A. MUÑOZ y G. PISANO (1990): La necrópolis fenicio-púnica de Cádiz. Siglos VI-IV a.C., Roma.

PEREIRA, J. (1989): “Necropolis ibéricas andaluzas. Nuevas perspectivas en su valoración y estudio"', Tartessos. Arqueología Protohistórica en el Bajo Guadalquivir, Barcelona, pp. 477-494.

RAKOB, F. (1983): “'Opus caementicium und die Folgen”, Mitteilungen des Romische Instituts, pp. 359-372.

ROLDAN, J.M. (1975): Itineraria Hispana, Valladolid-Granada. 
ROLDAN GOMEZ, L. (1992a): “Construcciones hidráulicas en Córdoba”, Homenaje al Prof. J.M. Blázquez, Madrid (en prensa).

ROLDAN GOMEZ, L. (1992b): “El acueducto de Nueva Carteya”, CupaUAM (en prensa).

ROLDAN GOMEZ, L. (1992c): Técnicas Arquitectónicas en la Bética Romana, Univ. Autónoma de Madrid (en prensa).

SANTOS, GENER, S. (1955): "Memoria de las excavaciones del Plan Nacional realizadas en Córdoba (1948-1950)". Informes y Memorias de la C.G.E.A., 31, Madrid.

SEAR, F. (1989): Roman Architecture, Londres.

SCHUBART, H. (1975): "Formación de colonias fenicias en la costa mediterránea", Saguntum, 11, Papeles de Laboratorio de arqueología, Valencia.

SCHUBART, H. y H.G. NIEMEYER (1976): Trayamar. Los hipogeos fenicios y el asentamiento de la desembocadura del río Algarrobo, Madrid.

SILLERES, P. (1991): Les Voies de Communication de l' Hispanie Meridionale, París.

SIRET, L. (1908): Villaricos y Herrerías. Antigüedades púnicas, romanas, visigóticas y árabes, M.R.A.H., XIV, Madrid.

STYLOW, A.U. (1990): "Apuntes sobre el urbanismo de la Corduba Romana", Stadtbild und Ideologie, Madrid, pp. 259-287.

THOUVENOT, R. (1973): Essai sur la province romaine de Bétique, París.

TORELLI, M. (1983): "Edilizia publica in Italia centrale fra guerra sociale e l'età augustea, ideología e classi sociale", Les bourgeoisies Municipales Italiennes aux II et I siecles av. J.C., pp. 241-250.

WAELKENS, M. (1987): "The Adoption of Roman Building Techniques in the Arquitecture of Asia Minor", Roman Architecture in the Greeck World, Londres, pp. 94-105. 


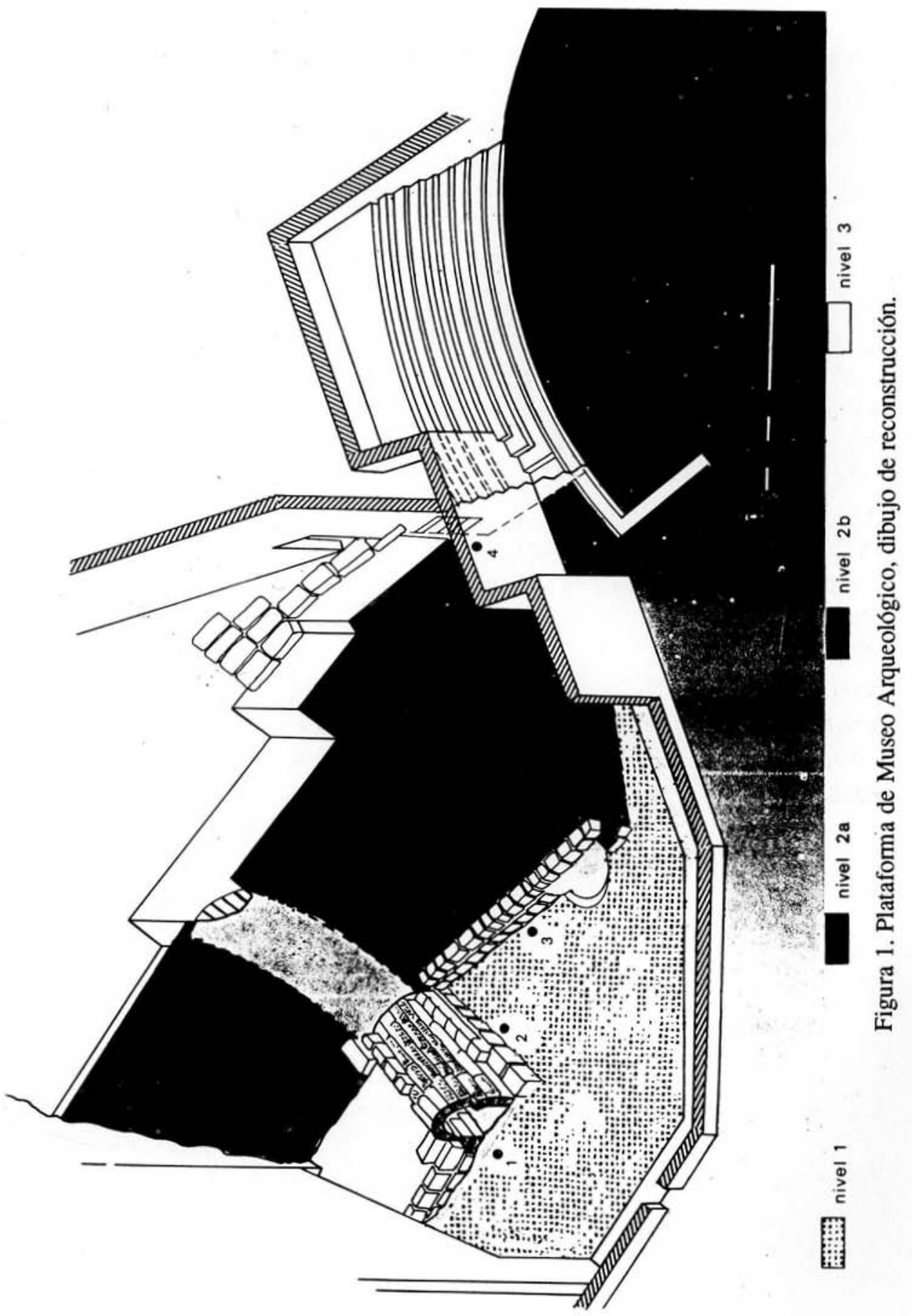




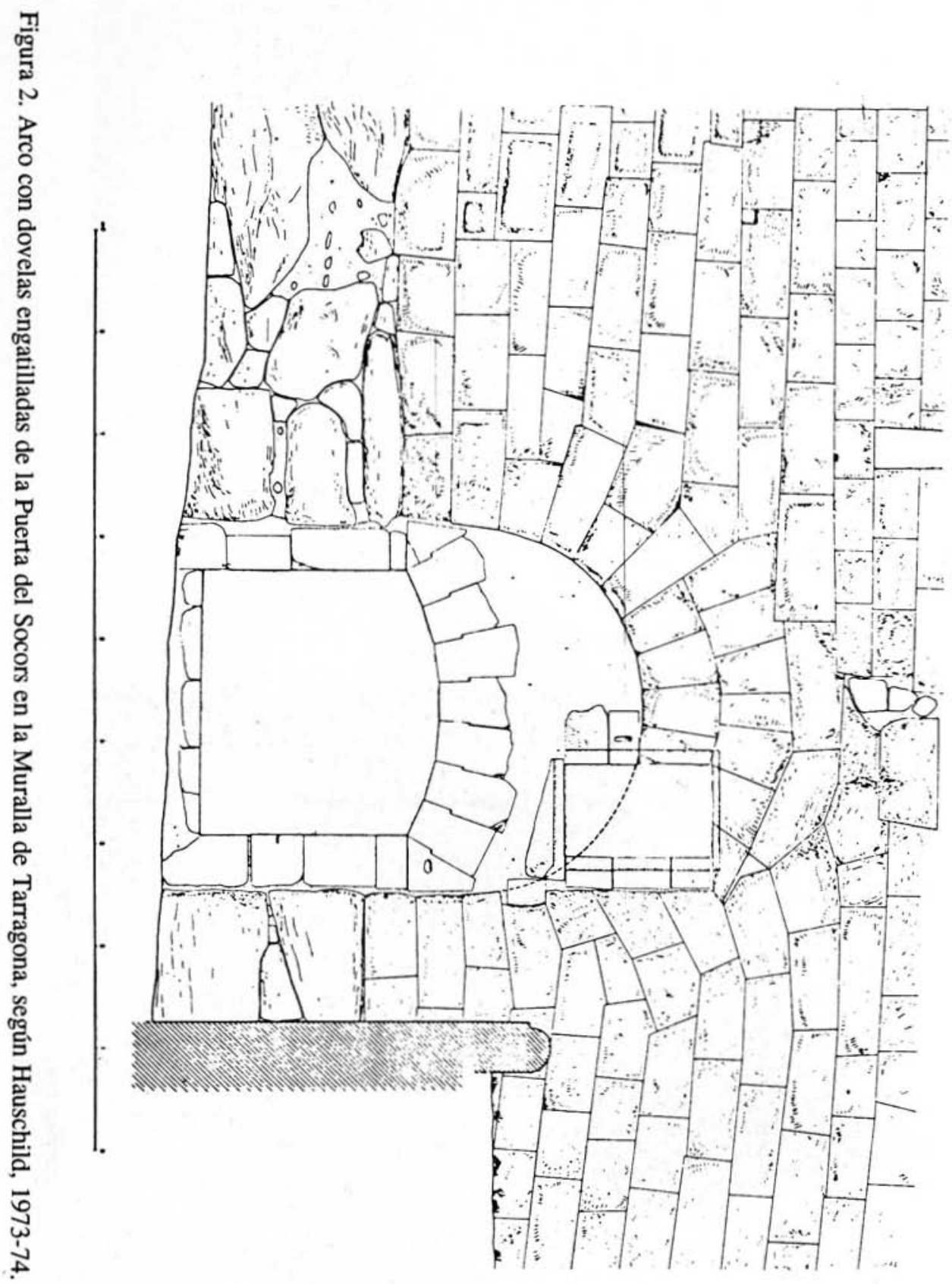



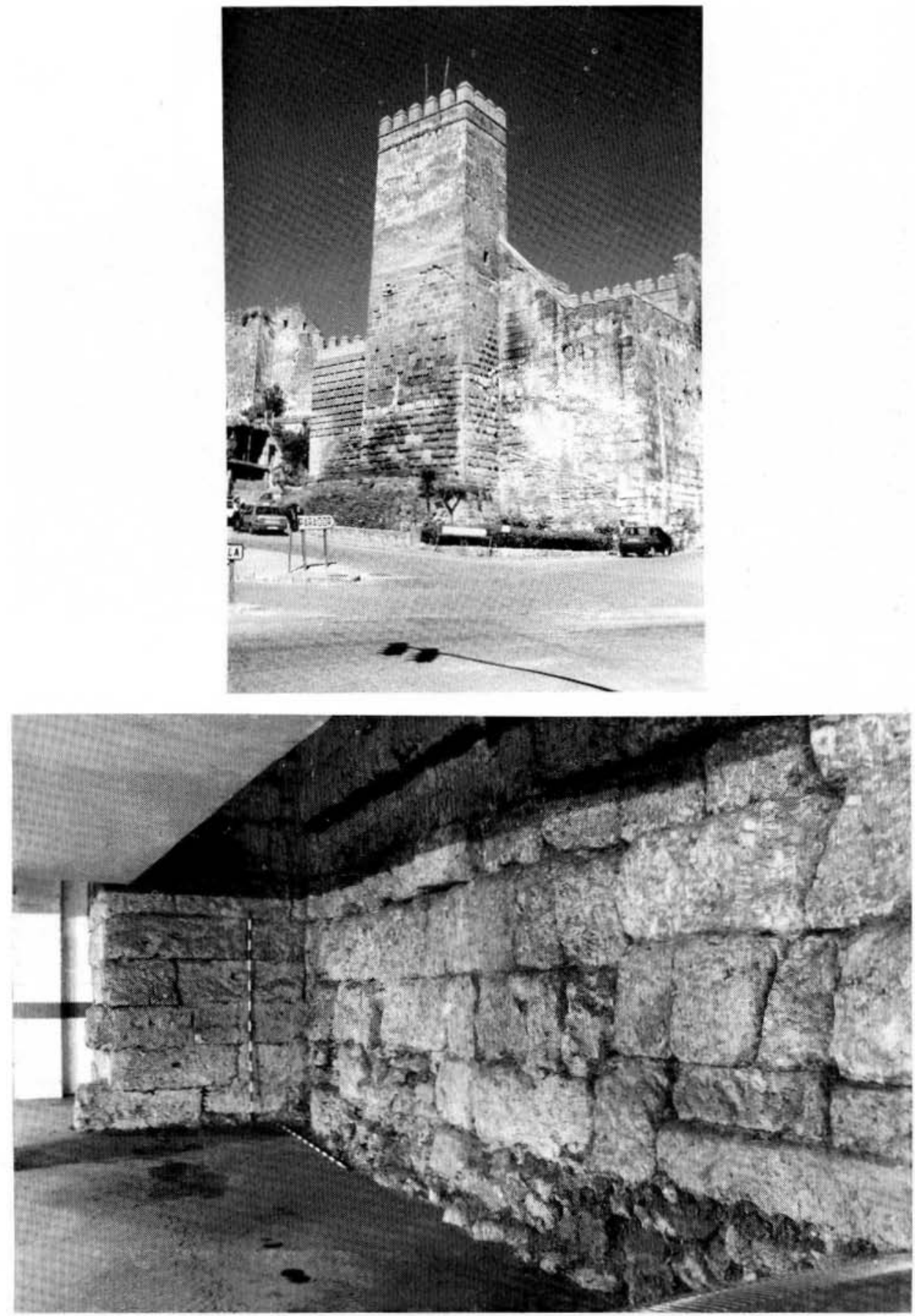

Lámina 1. a: Muralla de Carmona. Sillares de época púnica. b: Muralla de Córdoba. 

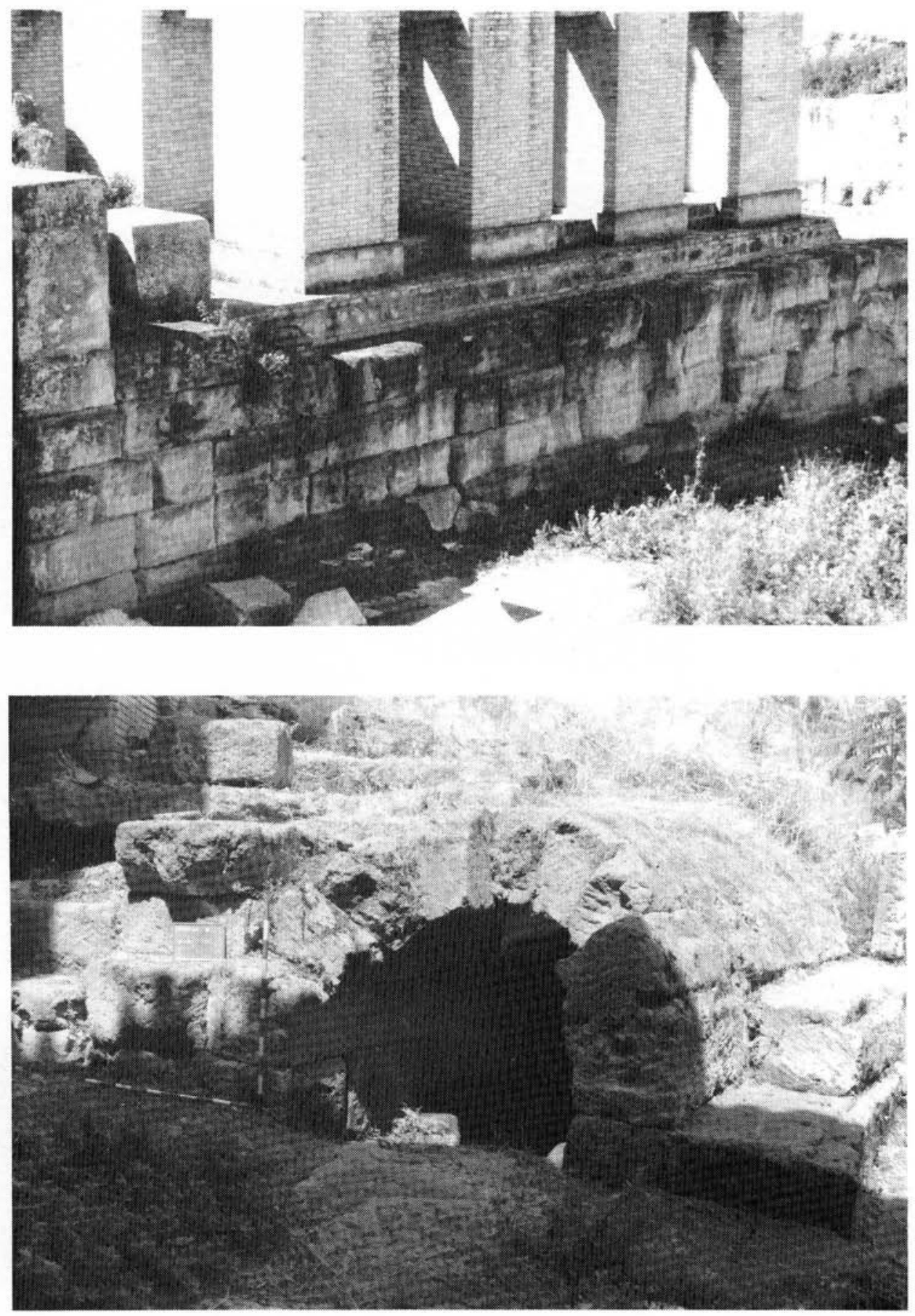

Lámina 2. a: Subestructura del templo.

b: Estructuras del Museo arqueologico, detalle frontal de los sillares. 

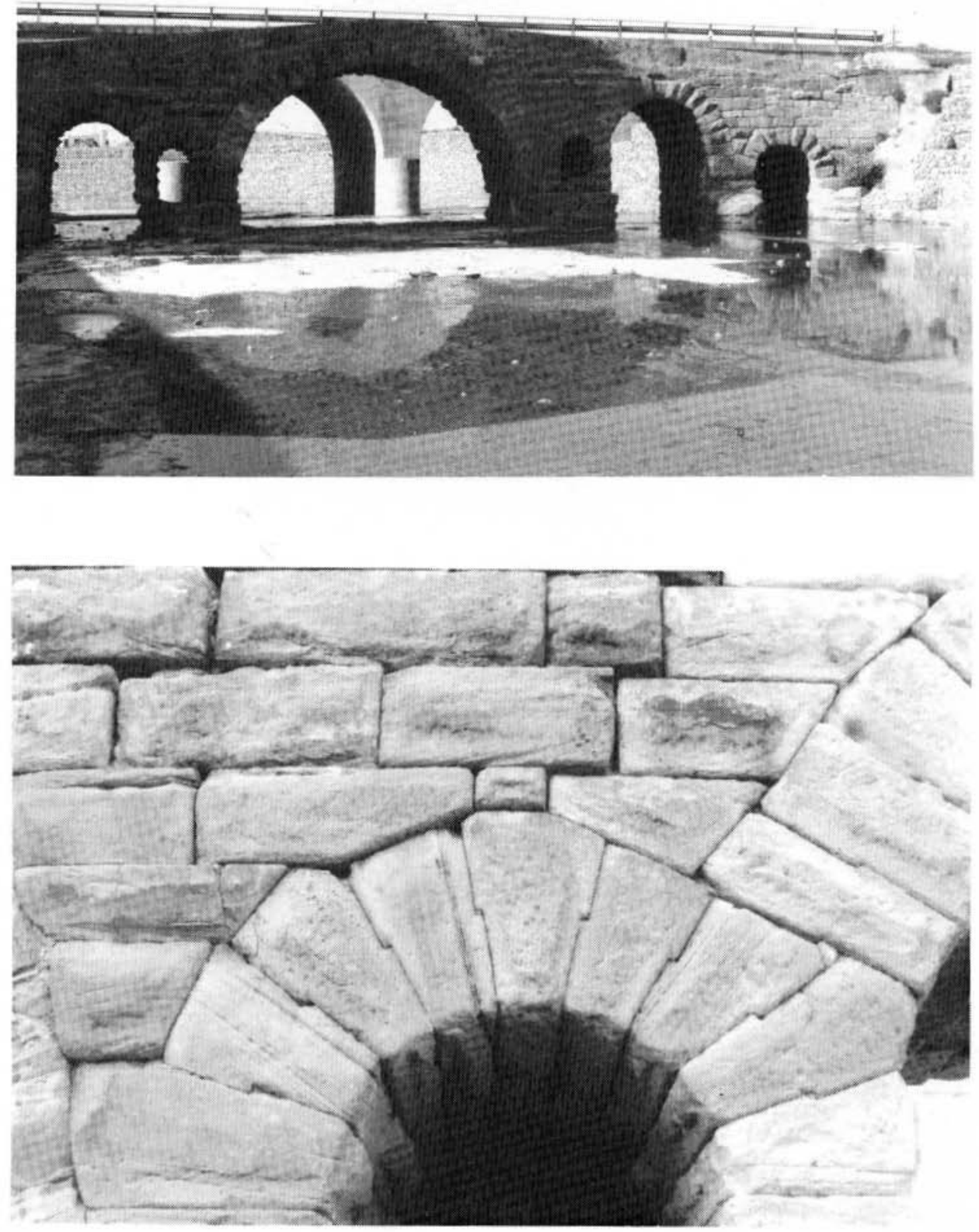

Lámina 3. a: Puente de Villa del Río, vista general.

b: Idem, detalle del arco lateral y arquillo de aligeramiento. 

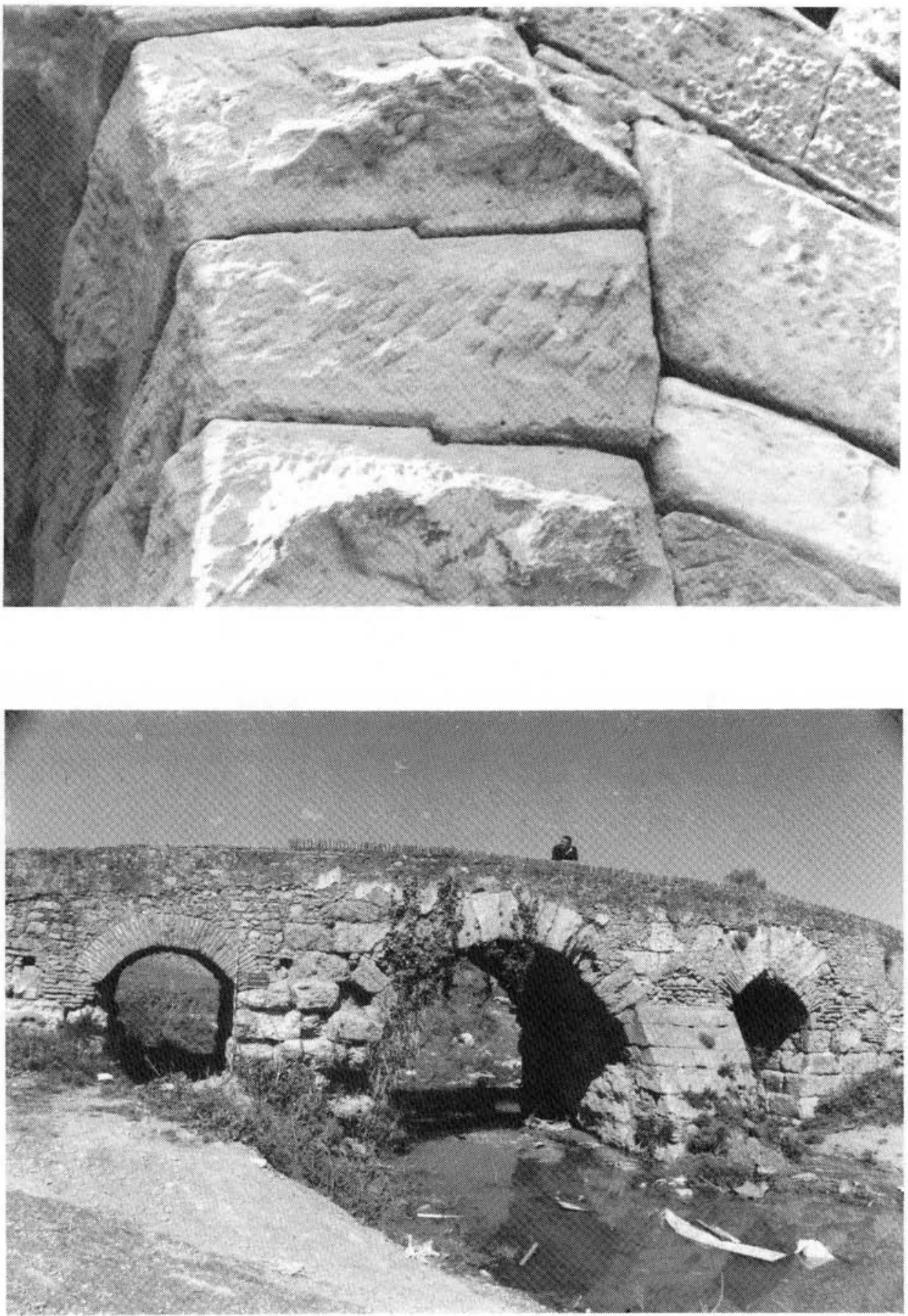

Lámina 4. a: Idem, detalle de los almohadillados y engatillado de las dovelas. b: Puente de Los Pedroches, vista general. 

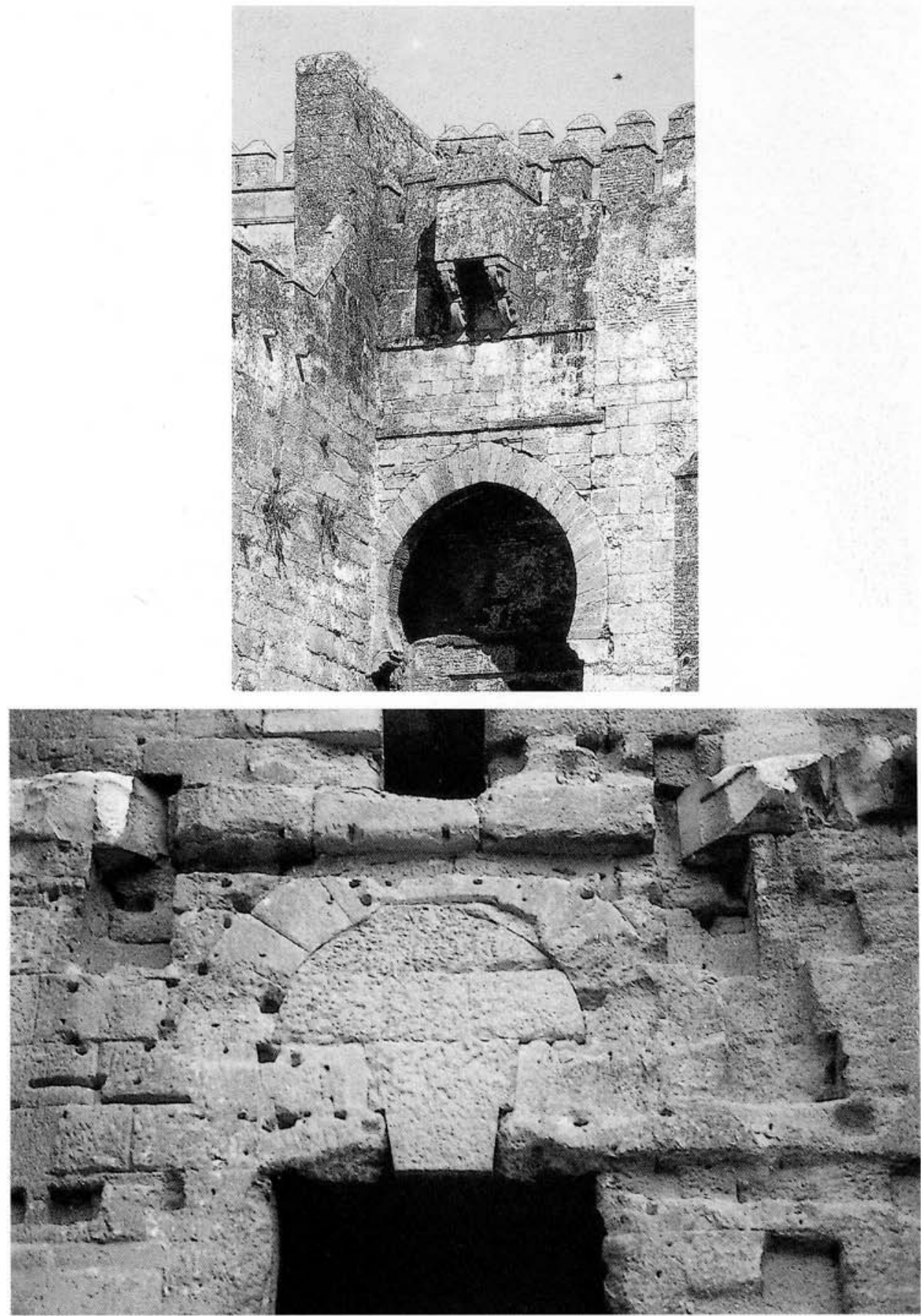

Lámina 5. a: Platabandas con sillares engatillados del teatro de Orange. b: Dovelas engatilladas en arco medieval de la Puerta de Sevilla en Carmona. 